\title{
IJMWT special issue on the 2009 National Microwave Days in France
}

\author{
PASCAL XAVIER, BÉATRICE CABON AND DOMINIQUE RAULY \\ Guest Editors
}

This special issue of International Journal of Microwave and Wireless Technologies is dedicated to topics discussed during the 16th Bi-annual French National Microwave Days (16th JNM) JNM'2009, held in Grenoble on 27-29 May 2009. It comprises 11 contributed papers selected out of over 60 JNM'2009 best communications.

The 16th JNM were organized in the Europole Congress Centre of Grenoble, France by the IMEP-LAHC Laboratory, Grenoble, France. This very successful event welcome 700 participants and consisted of oral and poster sessions focused on Antenna and Propagation, Passives Components Circuits and Devices, Actives Components and Integrated Circuits, Complex Systems, Instrumentation and Applications. It was also largely open to scientists from all countries.

The organizing committee was presided by Prof. P. Saguet, P. Ferrari, and A. Vilcot (IMEP-LAHC). We welcomed 700 participants and 124 papers were presented in 24 oral sessions, and 195 poster papers were presented in 10 poster sessions. These were selected from 360 submitted abstracts. These relatively severe acceptance rates illustrate the high technical level of the conference.

Two prizes were awarded for the best student papers, one for an oral presentation and one for a poster presentation:

\section{Claire Dalmay et al., XLIM Limoges}

"Méthode de Bio-détection basée sur la Spectroscopie Diélectrique Cellulaire aux Fréquences Radio- et Micro-ondes"

\section{Pierre Guillot et al., NXP Caen \& ESIEE Paris}

"Faisabilité de référence haute fréquence pour les architectures $R F^{\prime \prime}$

Many contributions were dealing with the design and characterization of RF passive components, antenna, and systems studies as well.

Shortly after the 16th JNM, this special issue of the International Journal of Microwave and Wireless Technologies, published by Cambridge University Press in collaboration with EuMA, covers the top results from the 16th JNM.

Sixty best papers presented on the 16th JNM have been selected and their authors have been proposed to submit their paper in this special issue. Forty-six international reviewers, among them 22 out of France scientific personalities, have been asked to review, and finally 11 of those papers were selected for publication in this special issue. We wish to acknowledge all of them for their in-depth evaluation of these papers (the first submission of papers occurred on 17th of june 2009, their final acceptance occurred on 23rd of September 2009). We also wish the readers nice and fruitful study of the content and hope that this special issue will give them scientific satisfaction and inspiration in their own research activities.

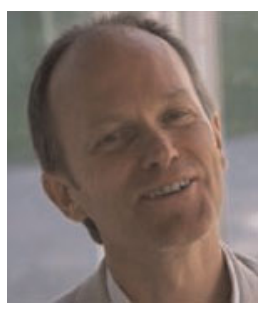

Pascal Xavier was born in France in 1964. He received the Ph.D. degree in Physics from the University Joseph FOURIER of Grenoble, France, in 1994. He was also graduated from the Polytechnical National Institute of Grenoble in Electrical Engineering in 1988. From 1994 to 2003 , in the Very Low Temperatures Research Centre of Grenoble (CRTBT CNRS), his research interests were dealing with numerical methods for the analysis of coupled thermo-electromagnetics problems (wavelets method of moments) and design of microsensors in the fields of microwaves. He joined the Research Institute of Microelectronics, Electromagnetism and Photonics (IMEP-LAHC) of Grenoble in 2003. His research interests include design, characterization, and realization of reconfigurable microwave devices, microwave sensors, and systems for environmental applications. He is Professor in the Department of Electrical Engineering, Technology University Institute of Grenoble, involved in teaching of Electronics and Physics.

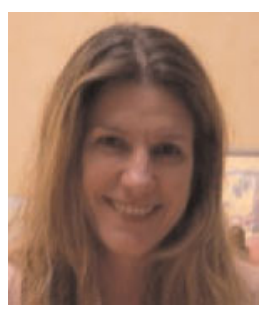

Béatrice Cabon (S'93-M'95) is a Professor at Grenoble-INP (National Polytechnics Institute of Grenoble, France). She received the Ph.D. degree in Microelectronics from the Institut National Polytechnique de Grenoble (INPG), Grenoble, France, in 1986. From 1986 to 1989 , she held a postdoctoral position with the National Center of Telecommunications, Grenoble, France. In 1989, she joined the Grenoble-INP, France. She was head of a 
research group on RF, Microwaves, Microwave-Photonics techniques at the IMEP-LAHC Laboratory in Grenoble, France (Institute for Microelectronics, Electromagnetism and Photonics). She has been coordinator of the club "optics and microwaves" of the French Optical Society (S.F.O) from 1999 to 2008. She has been coordinator of the IST-2001-32786 "NEFERTITI" (Network of Excellence on broadband Fiber Radio Techniques and its Integration Technologies) with 28 organizations over nine countries, funded by the European Commission (2002-2005). She has been also coordinator of the network of excellence FF6-IST-26592 "ISIS" (InfraStructures for broadband access in wireless/photonics and Integration of Strengths in Europe, www.ist-isis.org, 2006-2009) with 19 organizations of 12 countries. Her research interests include microwavephotonics, photonic-microwave signal processing, optical links for high bit rate signals. She has contributed to over 200 technical publications and is the Editor of four books in these areas.

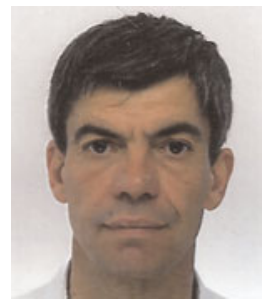

Dominique Rauly is an Associate Professor at the Academic Institute of Technology, of the Joseph Fourier University, Grenoble, France. He received a Ph.D. degree in Microwave Electronics from the National Polytechnic Institute of Grenoble. He worked on thermal management of microwave components within the Blaise Pascal University, Clermont-Ferrand, France, and with the Joseph Fourier University. He joined in 1998 the CRTBT (Centre de Recherche sur les Très Basses Températures) of the CNRS (Centre National de Recherche Scientifique) of Grenoble, working on microwave power sensors and TeraHertz characterization of high critical temperature superconductive thin films. Since 2006, his research deals with multi-band sub-millimetric bolometric detectors for the radio-astronomy, within the IMEP-LAHC (Institut de Microélectronique Electromagnétisme et Photonique, LAboratoire d'Hyperfréquences et de Caractérisation) of Grenoble. 